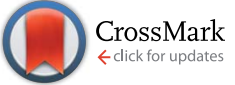

Cite this: RSC Adv., 2016, 6, 87128

Received 7th August 2016

Accepted 6th September 2016

DOI: 10.1039/c6ra19961e

www.rsc.org/advances

\section{Application of ferrocene-resorcinarene in silver nanoparticle synthesis $\uparrow$}

\author{
Tatiana Yu. Sergeeva, ${ }^{\text {ab }}$ Aida I. Samigullina, ${ }^{a}$ Aidar T. Gubaidullin, ${ }^{a}$ Irek R. Nizameev, ${ }^{a}$ \\ Marsil K. Kadirov, ${ }^{a}$ Rezeda K. Mukhitova, ${ }^{a}$ Albina Y. Ziganshina ${ }^{* a b}$ \\ and Alexander I. Konovalov ${ }^{\text {ab }}$
}

\begin{abstract}
An amphiphilic resorcinarene with ferrocene groups at the lower rim has been applied as both reductant and stabilizer in the synthesis of colloidal silver nanoparticles. The structure of the nanocomposite obtained was investigated by transmission electron microscopy, atomic force microscopy, X-ray powder diffraction, dynamic light scattering, and UV and IR spectroscopy. In the nanocomposite, the silver nanoparticles are stabilized by the multi-layers formed by ferrocene-resorcinarene. The diameter of the nanoparticles is $20-30 \mathrm{~nm}$ while the size of the nanocomposite is about $45 \mathrm{~nm}$. The nanoparticles demonstrate good catalytic activity for $p$-nitrophenol reduction. 40 nanomoles of the silver nanoparticles is sufficient to complete the reduction of $p$-nitrophenol over ten minutes.
\end{abstract}

\section{Introduction}

Nanosized noble metal particles (MNPs) exhibit specific properties when compared to their classical macroanalogues. A high surface-to-volume ratio and quantization effects cause the differences in the behavior of MNPs. ${ }^{1}$ Silver nanoparticles (AgNPs) have a long history and originally were used for coloring glasses. ${ }^{2}$ Subsequently, the range of their application has expanded significantly. Currently, the AgNPs are widely employed in chemistry, biology and medicine. ${ }^{3,4}$ The applications of AgNPs are mainly related to their localized surface plasmon resonance effect and their antibacterial properties. ${ }^{5-7}$ The surface plasmon resonance and intensity light scattering make AgNPs an ideal candidate for the molecular labeling especially in tomography. ${ }^{8}$ Due to antibacterial properties of AgNPs, there are attempts to include AgNPs in a wide range of medical devices: bone cement, surgical instruments, surgical masks and textiles. ${ }^{9}$ In addition to medical applications, AgNPs are utilized for indicating of structural and spatial isomers ${ }^{10,11}$ as well as catalysts in the oxidation, reduction or cycloaddition reactions and in the field of biomass conversion..$^{12-19}$

The properties of AgNPs depend on their size, shape and their surroundings..$^{20}$ Methods of preparing silver nanoparticles are well known. Most of them are based on the chemical reduction of silver ions and on the physical dispersion of

${ }^{a}$ Department of Supramolecular Chemistry, A. E. Arbuzov Institute of Organic and Physical Chemistry, Kazan Scientific Center, Russian Academy of Sciences, Arbuzov str.8, Kazan 420088, Russia.E-mail: az@iopc.ru

${ }^{b}$ A. M. Butlerov Institute of Chemistry, Kazan Federal University, Kremlevskaya str. 18, Kazan 420018, Russia

$\dagger$ Electronic supplementary information (ESI) available. See DOI: 10.1039/c6ra19961e a larger metal samples. ${ }^{21}$ The physical methods of AgNPs production require stringent conditions. Opposite to them, the chemical production of AgNPs proceeds in mild conditions. However, the organic methods are also deficient. The main problems are the formation of polydispersive AgNPs, sedimentation instability of their colloidal solutions and necessity of the usage of additional agents (stabilizers and reductants) in their synthesis.

Resorcinarenes are macrocyclic compounds obtained by the condensation of resorcinol with aldehydes. ${ }^{22}$ Functionalization of their upper and lower rims allows the synthesis of different type of building blocks for supramolecular architectures. The resorcinarene derivatives have found application in the separation technique ${ }^{23}$ and in the catalytic systems. ${ }^{24,25}$ Previously, it has been demonstrated that amphiphilic resorcinarenes are effective at extraction and stabilization of MNPs in organic solvents. ${ }^{26,27} \mathrm{~A}$ "macrocyclic effect" on the formation of AgNPs is discussed in the paper of A. E. Kaifer et al. ${ }^{28} \mathrm{E}$. Dalcanale et al. has reported the guest-controlled aggregation of MNPs covered with resorcinarene-cavitand. ${ }^{29}$

Due to the lipophilic properties, ferrocene and its derivatives are widely used as hydrophobic templates and building blocks for the creation of different supramolecular ${ }^{30,31}$ and molecular self-assembly structures. ${ }^{32-34}$ The lipophilic nature of the ferrocene can be switched to the hydrophilic one by the oxidation. This behavior was applied to the creation of the ferrocene based redox-responsive materials..$^{35-38}$ We have chosen a ferrocenecontaining resorcinarene with eight carboxyl groups at the upper rim (FcCA, Scheme 1) to obtain AgNPs. FcCA has several advantages for creation of AgNPs: (1) FcCA is well soluble in water, which allows to obtain AgNPs in aqueous media; (2) ferrocene groups exhibit reducing properties, ${ }^{38,39}$ so, FcCA can 


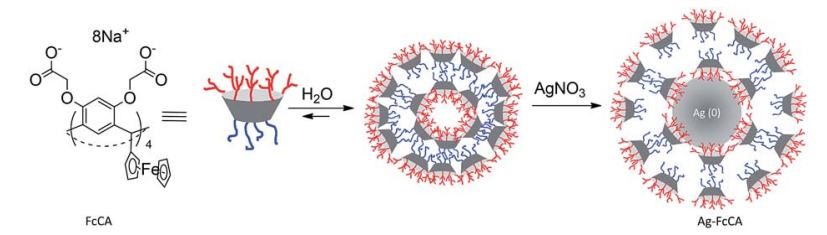

Scheme 1 Synthesis of AgNPs using the self-assembled resorcinarene FcCA.

reduce of $\mathrm{Ag}^{+}$to $\mathrm{Ag}^{0}$ without additional reducing agents; (3) FcCA can be used as a stabilizer of the colloidal AgNPs due to its amphiphilic properties; ${ }^{40}$ (4) the resorcinarene platform organizes functional groups of the upper rim which increases the binding efficiency of different substrates facilitating the substrate approach to the silver surface; (5) upper rim of the resorcinarene can be modified with multiply groups that produces silver nanoparticles coated with positively or negatively charged shells. ${ }^{41}$ Herein, we report a facilitate method for the synthesis of AgNPs in water using FcCA as reducing agent and stabilizer. The catalytic activity of the AgNPs obtained are investigated in the model reaction of the $p$-nitrophenol ( $p \mathrm{NPh})$ reduction..$^{42-45}$

\section{Experimental section}

\section{Materials}

Resorcinarene $\mathrm{FcCA}^{8-} \cdot 8 \mathrm{Na}^{+}$was synthesized using the known method. ${ }^{40}$ Silver nitrate (99+\%) was purchased from Alfa Aesar. 4-Nitrophenol (99.3\%) and sodium borohydride (99\%) were obtained from Acros Organics. All chemicals were used without further purification.

\section{Techniques}

X-ray powder diffraction (XRPD) measurements were performed on a Bruker D8 Advance diffractometer equipped with Vario attachment and Vantec linear PSD, using $\mathrm{Cu}$ radiation $(40 \mathrm{kV}$, $40 \mathrm{~mA}$ ) monochromated by the curved Johansson monochromator $\left(\lambda \mathrm{Cu} \mathrm{K} \alpha_{\alpha 1} 1.5406 \AA\right)$. Room-temperature data were collected in the reflection mode with a flat-plate sample. Sample was applied in liquid form on the surface of standard zero diffraction silicon plate. After drying the layer applied on top of it a few more layers to increase the total amount of sample. The sample was kept spinning (15 rpm) throughout the data collection. Patterns were recorded in the $2 \theta$ range between $3^{\circ}$ and $100^{\circ}$, in $0.008^{\circ}$ steps, with a step time of $0.1-0.5 \mathrm{~s}$. Several diffraction patterns in various experimental modes were collected for the sample. Processing of the obtained data performed using EVA $^{46}$ and TOPAS ${ }^{47}$ software packages. Powder X-ray diffraction database PDF-2 (ICDD PDF-2, Release 2005-2009) was used to identify the crystalline phase.

The transmission electron microscopy (TEM) images were obtained with Hitachi HT7700, Japan. The images were acquired at an accelerating voltage of $100 \mathrm{kV}$. Samples were on 300 mesh copper grids with continuous carbon-formvar support films.
An atomic force microscope (MultiMode V, USA) has been used to reveal the morphology of the nanoparticles. The 250-350 $\mathrm{kHz}$ canterlivers (Veeco, USA) with silicone tips (tip curvature radius is of 10-12 $\mathrm{nm}$ ) have been used in all measurements. The microscopic images were obtained with $512 \times 512$ resolution. The scanning rate was $1 \mathrm{~Hz}$. The antivibrational system (SG0508) has been used to eliminate external distortions. The tipconvolution effect has been minimized by processing the obtained AFM data with the use of the software (WSxM 5.0, Zod 2.0 and MatLAB). The method of tip-convolution effect minimizing is described in detail in ref. 48 and 49 . The calibration has been performed by the use of imaging special calibration grid (STR3$1800 \mathrm{P}$, VLSI Standards Inc.) in the temperature range $20-60{ }^{\circ} \mathrm{C}$.

UV-Vis absorption spectra were recorded using a PerkinElmer Lambda 25 UV-Vis spectrometer. IR spectra were recorded using a spectrometer Bruker Tensor 27. The hydrodynamic diameter and zeta potential were determined on a Malvern Zetasizer Nano instrument using the Malvern Dispersion Technology Software 5.10.

\section{Synthesis procedures}

$2.5 \mathrm{ml}$ of $0.1 \mathrm{mM} \mathrm{FcCA}^{8-} \cdot 8 \mathrm{Na}^{+}, 7.25 \mathrm{ml}$ of distilled water and $0.25 \mathrm{ml}$ of $10 \mathrm{mM} \mathrm{AgNO}_{3}$ were mixed and kept in an ultrasound bath at room temperature for 4 hours. The nanoparticles were isolated in solid state by ultracentrifugation at $15000 \mathrm{rpm}$ for $1.5 \mathrm{~h}$, washed with water and centrifuged again (3 times). Yield: 92\%. IR: $v(\mathrm{CH})=2924 \mathrm{~cm}^{21}, v_{\text {assim. }}(\mathrm{C}(\mathrm{O}) \mathrm{O})=1620 \mathrm{~cm}^{-1}, v_{\text {sim. }}$. $(\mathrm{C}(\mathrm{O}) \mathrm{O})=1400 \mathrm{~cm}^{-1}$.

For UV monitoring of the progress of the reaction, a sample was prepared as follows: to a quartz cuvette with the $1 \mathrm{~cm}$ optical length, $0.5 \mathrm{ml}$ solution of $0.1 \mathrm{mM} \mathrm{FcCA}^{8-} \cdot 8 \mathrm{Na}^{+}, 1.45 \mathrm{ml}$ of distilled water and $50 \mu \mathrm{l}$ of $10 \mathrm{mM} \mathrm{AgNO}{ }_{3}$ were added. UV spectra measurements were carried out for three hours. Solution of $\mathrm{FcCA}^{8-} \cdot 8 \mathrm{Na}$ with a concentration of $0.025 \mathrm{mM}$ was used as a blank.

\section{Varying the ratio of $\mathrm{AgNO}_{3} / \mathrm{FCCA}^{8-} \cdot \mathbf{8 \mathrm { Na } ^ { + }}$}

In a quartz cell with the $1 \mathrm{~cm}$ optical length, $0.5 \mathrm{ml}$ of $0.1 \mathrm{mM}$ $\mathrm{FcCA}^{8-} \cdot 8 \mathrm{Na}^{+}$and $0.05-0.5 \mathrm{ml}$ of $10 \mathrm{mM} \mathrm{AgNO}_{3}$ were mixtured and the volume of the mixture was adjusted to $2 \mathrm{ml}$. A $0.025 \mathrm{mM}$ solution of $\mathrm{FcCA}^{8-} \cdot 8 \mathrm{Na}$ was used as a blank. The reaction progress was monitored by UV spectroscopy.

\section{Catalytic properties}

In a quartz cell with the $0.5 \mathrm{~cm}$ optical length, $0.85 \mathrm{ml}$ of $0.2 \mathrm{mM}$ $p \mathrm{NPh}, 0.5 \mathrm{ml}$ of $0.15 \mathrm{M} \mathrm{NaBH}_{4}$ and $1.6 \mu \mathrm{l}$ of a freshly prepared colloidal solution of Ag-FCCA were mixture. The reduction process was monitored by UV spectroscopy.

\section{Results and discussion}

\section{Synthesis and characterization of Ag-FcCA}

The amphiphilic behavior and redox properties make FcCA the perspective agent in the synthesis of MNPs. FcCA self-assemblies in aqueous media ${ }^{40}$ and can act as a preorganizer and stabilizer of MNPs. The ferrocene groups of FcCA are strong reductants, ${ }^{40}$ 
i.e. they may be used for the reduction of various metal ions. When silver nitrates $(0.25 \mathrm{mM})$ are added to the FcCA micellar solution $(0.025 \mathrm{mM})$, the color turns to light yellow upon ultrasonication. In UV spectra, the appearance of an absorption band at $440 \mathrm{~nm}$ (Fig. 1) indicates the reduction of silver ions and the formation of AgNPs. ${ }^{50}$

The nanoparticles were isolated by centrifugation and washed with water followed by centrifugation several times. AgNPs obtained have a size about $30 \mathrm{~nm}$ as evident from the TEM image (Fig. 2). The AFM data show that the average size of the nanoparticles is approximately $60 \mathrm{~nm}$. The DLS data are in agreement with the AFM image. The hydrodynamic diameter is near $60 \mathrm{~nm}$ (Fig. 2). From the data obtained, it can be concluded that the nanoparticles have a core-shell structure (Ag-FcCA) where the silver core is stabilized with a shell consisting of the resorcinarene. AFM and DLS show the size of the whole nanocomposite while TEM demonstrates the size of AgNPs.

The XRPD data confirm the presence of a crystalline silver $\mathrm{Ag}^{0}$ in the nanocomposite $\mathrm{Ag}-\mathrm{FcCA}$ (Fig. 3A). The main interference peaks correspond to a cubic form of crystalline silver (Silver, syn., No. 01-087-0720 in the PDF database). The diffuse
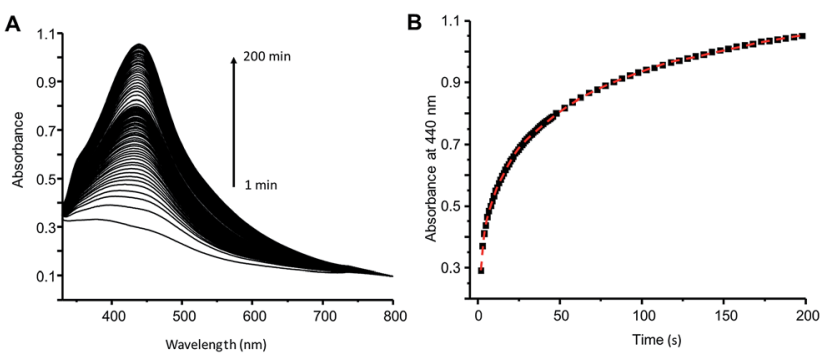

Fig. 1 (A) Temporal UV-Vis spectra changes of the reaction mixture of $\mathrm{AgNO}_{3}$ and $\mathrm{FcCA}$, (B) time-dependent absorbance at $440 \mathrm{~nm}$ $\left(C\left(\mathrm{AgNO}_{3}\right)=0.25 \mathrm{mM}, \mathrm{C}(\mathrm{FcCA})=0.025 \mathrm{mM}, \mathrm{H}_{2} \mathrm{O}, 25^{\circ} \mathrm{C}, l=1 \mathrm{~cm}\right)$.
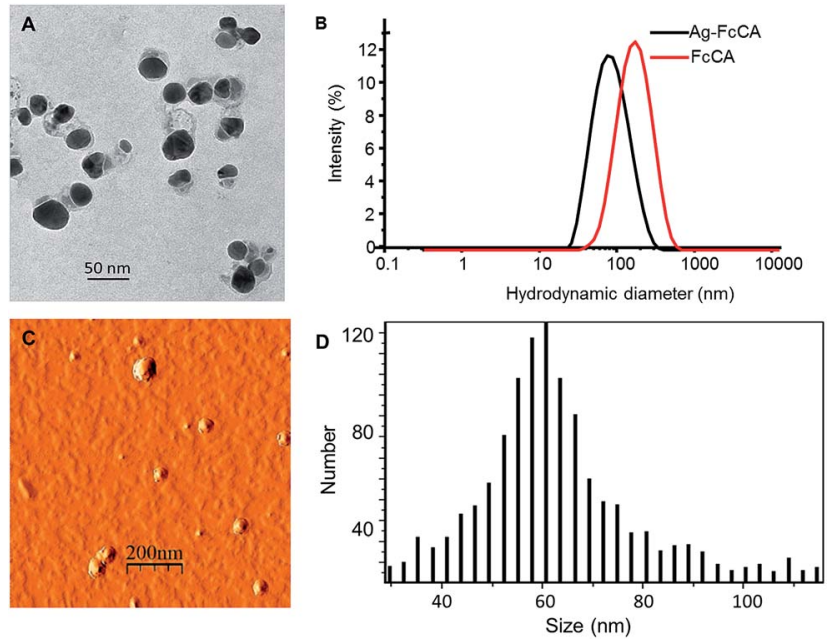

Fig. 2 (A) TEM image of $\mathrm{Ag}_{10}-\mathrm{FCCA}$; (B) hydrodynamic diameters of $\mathrm{Ag}-\mathrm{FcCA}\left(\mathrm{C}=0.09 \mathrm{mg} \mathrm{ml}^{-1}\right.$, bleak line $)$ and FCCA $(C=0.1 \mathrm{mM}$, red line), DLS data; (C) AFM image of $\mathrm{Ag}_{10}-\mathrm{FCCA}$ on a mica surface and (D) the particles lateral sizes distribution, AFM data.

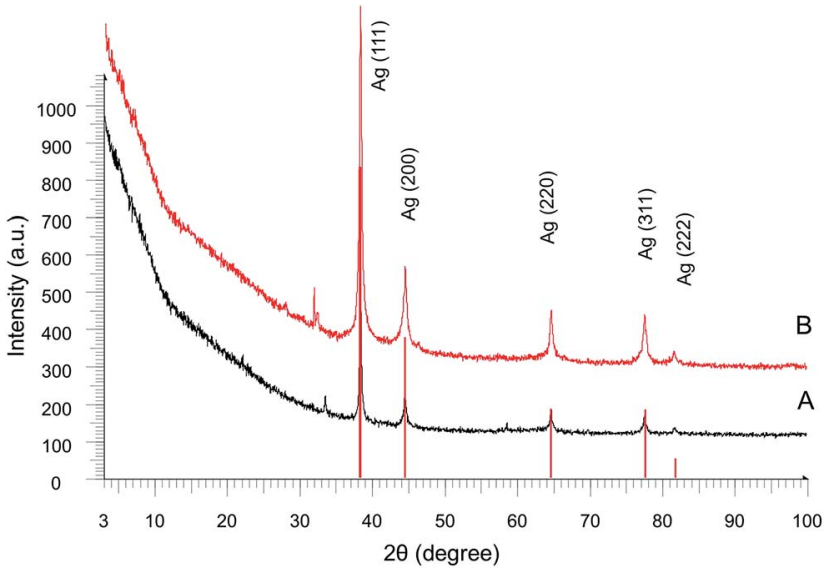

Fig. 3 Experimental diffraction patterns of (A) $\mathrm{Ag}_{10}-\mathrm{FcCA}$ and (B) $\mathrm{Ag}_{30}-\mathrm{FcCA}$ without background subtraction. Red vertical lines show the position of the interference peaks corresponding to a crystalline silver (Silver, syn., No. 01-087-0720 in the PDF database).

nature of most of the diffraction peaks in the diffractogram indicates very small linear dimensions of the silver crystallites, that is the nanostructuredness of Ag-FcCA. The mean dimensions of the silver crystallites calculated from the interference peaks wide are in the range of $12-23 \mathrm{~nm}$.

$\mathrm{Ag}-\mathrm{FcCA}$ is stable in water without particle aggregation at room temperature for at least three months. In UV spectra sensitive to the segmentation of AgNPs, ${ }^{51}$ there are no significant changes after the storage of the colloidal Ag-FcCA indicating of its high kinetic stability (Fig. S1 in the ESI $\dagger$ ). The reason of the Ag-FcCA stability is the multicharged surface formed by the carboxylate groups of FcCA. The zeta-potential of $\mathrm{Ag}-\mathrm{FcCA}$ is $-57 \mathrm{mV}$ (Fig. S2 in the ESI $\dagger$ ). It is much lower than that of the FcCA aggregates $(-47 \mathrm{mV})$ demonstrating greater sustainability of Ag-FcCA. As it is well known, AgNPs grow under the irradiation with the wavelength corresponding to their plasmon resonance. ${ }^{52}$ FcCA protects AgNPs preventing them from the growing as it is clearly seen from the equivalence of the UV spectra after the three hours irradiation at $450 \mathrm{~nm}$ (Fig. S3 in the ESI $\dagger$ ).

The kinetic curve of the Ag-FcCA formation has a complex shape due to the multistage reduction processes (Fig. 1). Initially the ferrocenes oxidation and the reduction of silver ions occurs. Ferrocenium ion formed during the oxidation is not stable in the water and decompose to the Fe(II) species and cyclopentadienyl radicals. ${ }^{5-55}$ The active components react with the next silver ions to produce metallic silver. In IR spectrum decreasing of the metal-ring vibration signal of ferrocene at $482 \mathrm{~cm}^{-1}$ confirms the destruction of the ferrocene groups (Fig. 4B). The vibration signals of the resorcinarene skeleton at $1607 \mathrm{~cm}^{-1}(\mathrm{C}=\mathrm{C}$ aromatic bonds) and $1419 \mathrm{~cm}^{-1}$ (-CH methine bridge) are not changed, indicating preservation of the integrity of the macrocyclic frame.

However, the incomplete disappearance of the ferrocene vibration band at $482 \mathrm{~cm}^{-1}$ has prompted us to investigate the optimal ratio of FcCA and $\mathrm{AgNO}_{3}$ in the synthesis of AgNPs. We varied the reactants molar ratio with a constant concentration 


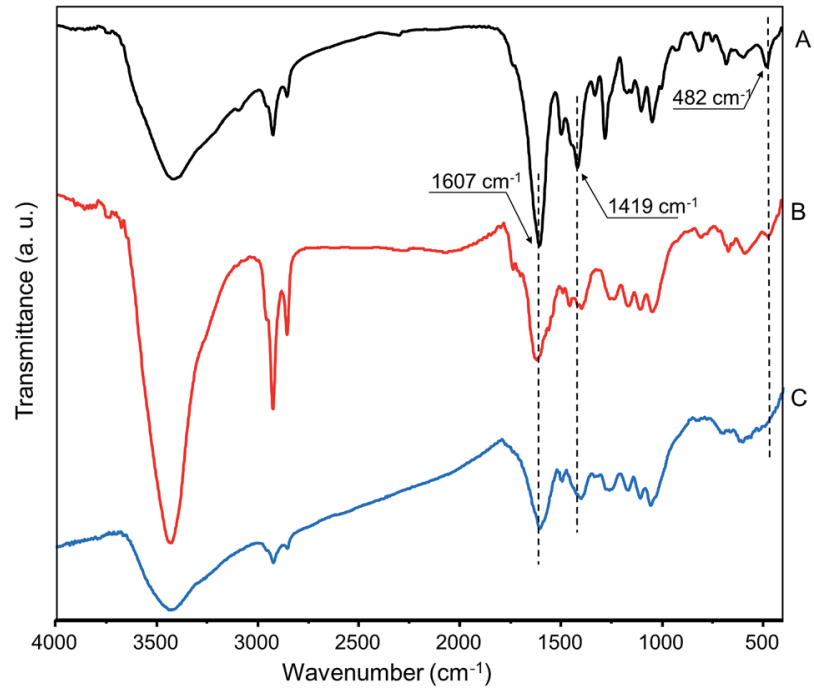

Fig. 4 IR-spectra of (A) FcCA, (B) $\mathrm{Ag}_{10}-\mathrm{FcCA}$ and (C) $\mathrm{Ag}_{30}-\mathrm{FcCA}$.

of the FcCA $(0.025 \mathrm{mM})$ and a various concentration of $\mathrm{AgNO}_{3}$ $(0.25 \div 2.5 \mathrm{mM})$. Fig. 5 shows UV-spectra of the samples obtained. A maximum absorption at $440 \mathrm{~nm}$ occurs for all ratio of $\mathrm{AgNO}_{3}$ and FcCA, indicating to the formation of silver nanoparticles with same size and shape. The absorbance of the samples with $20: 1$ and $30: 1$ ratio $\left(\mathrm{AgNO}_{3}: \mathrm{FcCA}\right.$ respectively) is about two and three times greater than that for the $10: 1$. The next increase of the silver ions amount does not increases the absorption of the silver nanoparticle. Using 30-fold excess of $\mathrm{AgNO}_{3}\left(\mathrm{Ag}_{30}-\mathrm{FcCA}\right)$ results in the complete destruction of ferrocene groups as evident from IR spectrum (Fig. 4C).

The XRPD analysis show that the $\mathrm{Ag}_{30}$-FcCA has the same structure as $\mathrm{Ag}_{10}-\mathrm{FcCA}$ with the use of 10-fold excess of $\mathrm{AgNO}_{3}$ (Fig. 3B). The size of the silver crystallites in $\mathrm{Ag}_{30}-\mathrm{FcCA}$ is 19-33 nm. The amount of crystalline silver in $\mathrm{Ag}_{10}-\mathrm{FcCA}$ and $\mathrm{Ag}_{30}-\mathrm{FcCA}$ is equal to $83.4 \%$ and $81.2 \%$ correspondingly. Furthermore, both nanocomposites contain small amount of the other crystalline materials.

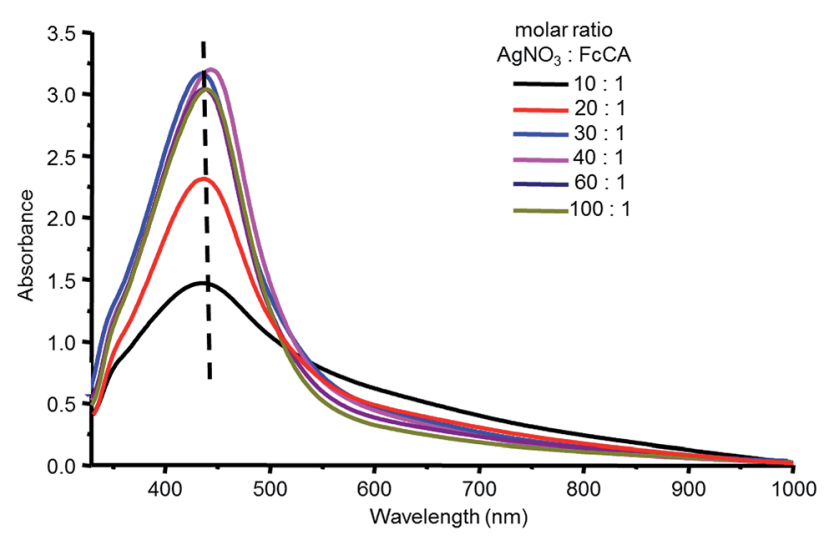

Fig. 5 UV-Vis spectra of the AgNPs solutions for different molar ratio of $\mathrm{AgNO}_{3}(C=0.25 \div 2.5 \mathrm{mM})$ and FcCA $(C=0.025 \mathrm{mM})$. The spectra are recorded on the second day of the reaction $\left(\mathrm{H}_{2} \mathrm{O}, 25^{\circ} \mathrm{C}, l=1 \mathrm{~cm}\right)$.
The XRD database search did not give a clear identification of the crystalline compounds additionally contained in $\mathrm{Ag}_{10^{-}}$ FcCA and $\mathrm{Ag}_{30}-$ FcCA. Small intensity peaks in the diffractograms can be attributed to a number of crystalline materials with equal probability. However, a careful analysis of the data obtained allows us to make some general conclusions. Firstly, the comparison of the two diffraction patterns shows that the additional crystalline components are different for $\mathrm{Ag}_{10}-\mathrm{FcCA}$ and $\mathrm{Ag}_{30}-\mathrm{FcCA}$ (Fig. S4 in the ESI $\dagger$ ). In the case of $\mathrm{Ag}_{10}-\mathrm{FcCA}$ (curve A in Fig. S4 in ESI $\dagger$ ), the secondary peaks in the range of $2 \theta=30-32^{\circ}$ can be assigned to FcCA (curve C in Fig. S4 in ESI $\dagger$ ). However, additional peaks in the $\mathrm{Ag}_{30}-\mathrm{FcCA}$ diffractogram (curve B in Fig. S4 in ESI $\dagger$ ) are characteristic not only for the FcCA, but also for a number of crystalline compounds whose presence in $\mathrm{Ag}_{30}-\mathrm{FcCA}$ is possible (curve $\mathrm{B}$ in Fig. $\mathrm{S} 4$ in the $\mathrm{ESI} \dagger$ ). Notable, that FcCA exhibits a diffraction pattern which is characteristic for an amorphous-crystalline compound with an intensive background fluorescence due to the iron scattering on copper radiation. In the $\mathrm{Ag}_{10}-\mathrm{FcCA}$ and $\mathrm{Ag}_{30}-\mathrm{FcCA}$ patterns, the fluorescence background is minimal. So, it can be assumed that the amount of the iron-containing component in $\mathrm{Ag}_{10}-\mathrm{FcCA}$ and $\mathrm{Ag}_{30}-\mathrm{FcCA}$ is negligible.

According to the UV data jointly with XRPD analysis, the size of AgNPs formed does not depends on the ratio of $\mathrm{AgNO}_{3}$ and FcCA. The nanoparticles of the same size are produced by using a various concentration of silver ions $C=0.25 \div 2.5 \mathrm{mM}$. Apparently, an assembly of FcCA in water plays a key role in forming of one type of AgNPs. Increasing the FcCA concentration results in the formation of a larger amount of AgNPs, which are not stable in water and precipitate.

From these results, it can be concluded that FcCA efficiently reduces silver ions to form the nanosized crystalline silver particles. The reduction is a complex process after which the ferrocene moieties of FcCA are completely destroyed. The remaining resorcinarene carcass cover the silver nanoparticles, making them well soluble and stable in water. Using an excess amount of silver ion is more preferable to produce AgNPs with better monodispersity. An excess of the reagents and byproducts can be easily removed by the repeated washing of the nanocomposites with water followed by the centrifugation.

\section{Catalytic properties of Ag-FcCA}

The catalytic properties of Ag-FcCA were studied on the reaction of the $p \mathrm{NPh}$ reduction with sodium borohydride. The $p \mathrm{NPh}$ reduction is widely used as a model reaction for investigating noble metal nanoparticles catalytic activity. ${ }^{42-45}$ The reaction can be easily monitored by UV spectroscopy.

The $p \mathrm{NPh}$ reduction does not occur in the absence of a catalyst. Addition of Ag-FcCA (40 nanomoles) to a mixture of $p \mathrm{NPh}$ $(0.113 \mathrm{mM})$ and sodium borohydride $(0.5 \mathrm{M})$ results in the $p$ aminophenol formation. The reaction is completed within 15 minutes (Fig. 6). The pseudo-first-order rate constant was determined as a function of $p \mathrm{NPh}$ concentration. The rate constant and catalytic activity of $\mathrm{Ag}-\mathrm{FcCA}$ were calculated from the slope of the linear dependence between the natural logarithm of the absorbance at $400 \mathrm{~nm}$ and time (Fig. S5 in the ESI $\dagger$ ). 


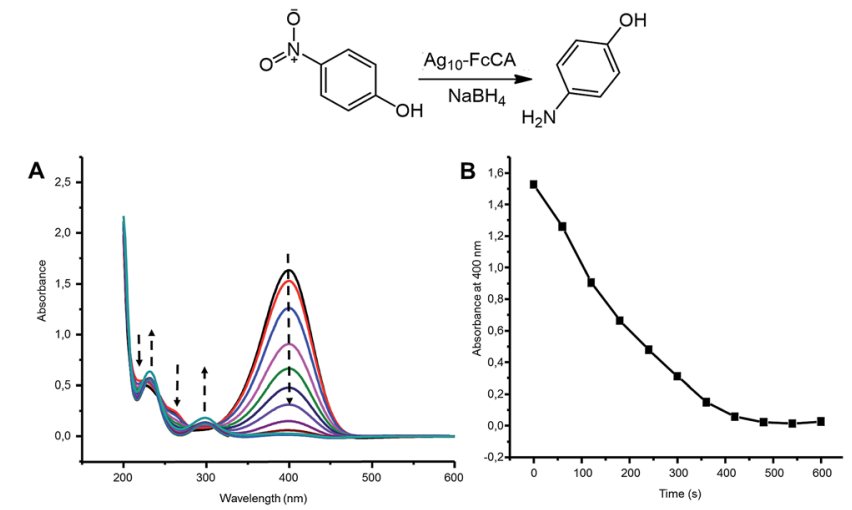

Fig. 6 (A) Time-dependent UV-Vis spectra of the pNPh reduction in the presence of 40 nanomole of $\mathrm{Ag}_{10}-\mathrm{FcCA}$, (B) changes in absorption at $400 \mathrm{~nm}\left(\mathrm{C}(\mathrm{pNPh})=0.113 \mathrm{mM}, \mathrm{C}\left(\mathrm{NaBH}_{4}\right)=0.5 \mathrm{M}, \mathrm{H}_{2} \mathrm{O}, 25^{\circ} \mathrm{C}, l=0.5\right.$ $\mathrm{cm})$.

The reaction rate constant is $0.0028 \mathrm{~s}^{-1}$ and the catalytic activity is $70000 \mathrm{~mol} \mathrm{~s}^{-1}$. It is known that the catalytic properties of MNPs depends on their size. ${ }^{56,57}$ The smaller MNPs exhibit better catalytic activity. In our case, silver nanoparticles in Ag-FcCA are relatively large (about $30 \mathrm{~nm}$ ) and, therefore, they should not be catalytically effective. However, the catalytic activity of Ag-FcCA is comparable with the smaller AgNPs (10-15 nm) stabilized with surfactants and polymers. ${ }^{56}$ Apparently, due to the specific threedimensional structure, FcCA forms a loose packing structure at the AgNPs surface which facilitates the approach of reagents to the metal surface. Thus, despite the relatively large size and the FcCA stabilizing shell, Ag-FcCA shows good catalytic activity commensurate with the previously reported..$^{56-58}$

\section{Conclusions}

An amphiphilic derivative of ferrocene-resorcinarene was used as a template and reducing agent for the synthesis of silver nanoparticles. The silver nanoparticles obtained and stabilized with the destructurized resorcinarene to form a nanocomposite with high kinetic stability. The synthesized nanocomposite shows good catalytic activity in the reduction reaction of $p$ nitrophenol.

\section{Acknowledgements}

This study was supported by the Russian Foundation for Basic Research (grant 15-03-04999).

\section{Notes and references}

1 B. Wiley, Y. Sun, B. Mayers and Y. XiaShape, Chem.-Eur. J., 2005, 11, 454-463.

2 K. Nassau, The Physics and Chemistry of Color: The Fifteen Causes of Color, Wiley, New York, 2001.

3 X.-R. Song, N. Goswami, H.-H. Yang and J. Xie, Analyst, 2016, 141, 3126-3140.
4 K. Zheng, X. Yuan, N. Goswami, Q. Zhang and J. Xie, RSC Adv., 2014, 4, 60581-60596.

5 Z. Xiu, Q. Zhang, H. L. Puppala, V. L. Colvin and J. J. Alvarez Pedro, Nano Lett., 2012, 12, 4271-4275.

6 P. Anger, P. Bharadwaj and L. Novotny, Phys. Rev. Lett., 2006, 96, 113002-113004.

7 K. Zheng, M. I. Setyawati, T.-P. Lim, D. T. Leong and J. Xie, ACS Nano, 2016, 10, 7934-7942.

8 Q. H. Tran, V. Q. Nguyen and A.-T. Li, Adv. Nat. Sci.: Nanosci. Nanotechnol., 2013, 4, 033001-033020.

9 I. Armentano and J. M. Kenny, Silver nanoparticles: synthesis, uses and health concerns, Nova Science Publishers Inc, New York, 2013.

10 S. Abalde-Cela, J. M. Hermida-Ramón, P. ContrerasCarballada, L. De Cola, A. Guerrero-Martínez, R. A. AlvarezPuebla and L. M. Liz-Marzán, ChemPhysChem, 2011, 12, 1529-1535.

11 X. Chen, S. G. Parker, G. Zou, W. Su and G. Zhang, ACS Nano, 2012, 4, 6387-6394.

12 J. Fang, B. Zhang, Q. Yao, Y. Yang, J. Xie and N. Yan, Coord. Chem. Rev., 2016, 322, 1-29.

13 N. Yan, Y. Yuan and P. J. Dyson, Dalton Trans., 2013, 42, 13294-13304.

14 V. K. Vidhu and D. Philip, Micron, 2014, 56, 54-62.

15 S. Sh. Kuan, K. Ch. Young, Ch. Jeong-Yong and K. Kwan, Appl. Catal., A, 2012, 414, 170-175.

16 L. C. Charles-Oneil, G. L. Hallett-Tapley, M. Frenette, M. González-Béja, J. C. Netto-Ferreira and J. C. Scaiano, ACS Catal., 2013, 3, 2062-2071.

17 H. Cong, C. F. Becker, S. J. Elliott, M. W. Grinstaff and J. A. Porco, J. Am. Chem. Soc., 2010, 132, 7514-7518.

18 Y. Wang, S. De and N. Yan, Chem. Commun., 2016, 52, 62106224.

19 B. Zhang, J. Fang, J. Li, J. J. Lau, D. Mattia, Z. Zhong, J. Xie and N. Yan, Chem.-Asian J., 2016, 11, 532-539.

20 A. R. Tao, S. Habas and P. Yang, Small, 2008, 3, 310-325.

21 S. Prabhu and E. K. Poulose, Int. Nano Lett., 2012, 2, 32-42.

22 W. Sliwa and C. Kozlowski, Calixarenes and Resorcinarenes: Synthesis, Properties and Application, Wiley-VCH, Weinheim2009.

23 N. Li, R. G. Harrison and J. D. Lamb, J. Inclusion Phenom. Macrocyclic Chem., 2014, 78, 39-60.

24 Q. Zhang and K. Tiefenbacher, Nature Chem., 2015, 7, 197202.

25 A. Cavarzan, A. Scarso, P. Sgarbossa, G. Strukul and J. N. H. Reek, J. Am. Chem. Soc., 2011, 133, 2848-2851.

26 A. Wei, Chem. Commun., 2006, 1581-1591.

27 V. Montes-García, J. Pérez-Juste, I. Pastoriza-Santos and L. M. Liz-Marzán, Chem.-Eur. J., 2014, 20, 10874-10883.

28 J. Liu, W. Ong and A. E. Kaifer, Langmuir, 2002, 18, 59815983.

29 M. Dionisio, F. Maffei, E. Rampazzo, L. Prodi, A. Pucci, G. Ruggeri and E. Dalcanale, Chem. Commun., 2011, 47, 6596-6598.

30 A. V. Mossine, H. Kumari, D. A. Fowler, A. K. Maerz, S. R. Kline, Ch. L. Barnes and J. L. Atwood, Isr. J. Chem., 2011, 51, 840-842. 
31 Q. Duan, Y. Cao, Y. Li, X. Hu, T. Xiao, C. Lin, Y. Pan and L. Wang, J. Am. Chem. Soc., 2013, 135, 10542-10549.

32 L. Liu, L. Rui, Y. Gao and Z. Zhang, Polym. Chem., 2015, 6, 1817-1829.

33 Zh.-P. Xiao, Zh.-H. Cai, H. Liang and J. Lu, J. Mater. Chem., 2010, 20, 8375-8381.

34 J.-Ch. Eloi, D. A. Rider, G. Cambridge, G. R. Whittell, M. A. Winnik and I. Manners, J. Am. Chem. Soc., 2011, 133, 8903-8913.

35 M. Nakahata, Y. Takashima, H. Yamaguchi and A. Harada, Nat. Commun., 2011, 2, 511-516.

36 R. H. Staff, M. Gallei, M. Mazurowski, M. Rehahn, R. Berger, K. Landfester and D. Crespy, ACS Nano, 2012, 6, 9042-9049.

37 Y. Ahn, Y. Jang, N. Selvapalam, G. Yun and K. Kim, Angew. Chem., 2013, 125, 3222-3226.

38 B. Zoetebier, M. A. Hempenius and G. J. Vancso, Chem. Commun., 2015, 51, 636-639.

39 L. Zhu, Y. Shangguan, Y. Sun, J. Ji and Q. Zheng, Soft Matter, 2010, 6, 5541-5546.

40 D. E. Korshin, N. V. Nastapova, S. V. Kharlamov, G. R. Nasybullina, T. Yu. Sergeeva, E. G. Krasnova, E. D. Sultanova, R. K. Mukhitova, Sh. K. Latypov, V. V. Yanilkin, A. Y. Ziganshina and A. I. Konovalov, Mendeleev Commun., 2013, 23, 71-73.

41 A. Wei, B. Kim, S. V. Pusztay, S. L. Tripp and R. Balasubramanian, J. Inclusion Phenom. Macrocyclic Chem., 2001, 41, 83-86.

42 P. Hervés, M. Pérez-Lorenzo, L. M. Liz-Marzán, J. Y. Dzubiella, Y. Lu and M. Ballauff, Chem. Soc. Rev., 2012, 41, 5577-5587.

43 P. Lara and K. Philippot, Catal. Sci. Technol., 2014, 4, 24452465.
$44 \mathrm{~S} . \mathrm{Gu}, \mathrm{S}$. Wunder, Y. Lu, M. Ballauff, R. Fenger, K. Rademann, D. Jaquet and A. Zaccone, J. Phys. Chem. C, 2014, 118, 18618-18625.

45 T. Aditya, A. Pal and T. Pal, Chem. Commun., 2015, 51, 94109431.

46 DIFFRAC Plus Evaluation package EVA, Version 11, User's Manual, Bruker AXS, Karlsruhe, Germany, 2005.

47 TOPAS V3: General profile and structure analysis software for powder diffraction data, Technical Reference, Bruker AXS, Karlsruhe, Germany, 2005.

48 M. K. Kadirov, I. R. Nizameev and L. Ya. Zakharova, J. Phys. Chem. C, 2012, 116, 11326-11335.

49 M. K. Kadirov, A. I. Litvinov, I. R. Nizameev and L. Y. Zakharova, J. Phys. Chem. C, 2014, 118, 19785-19794. 50 T. Dadosh, Mater. Lett., 2009, 63, 2236-2238.

51 T. C. Prathna, N. Chandrasekaran and A. Mukherjee, Colloids Surf., A, 2011, 390, 216-224.

52 H. Jia, W. Xu, J. An, D. Li and B. Zhao, Spectrochim. Acta, Part A, 2006, 64, 956-960.

53 G. Tabbí, C. Cassino, G. Cavigiolio, D. Colangelo, A. Ghiglia, I. Viano and D. Osella, J. Med. Chem., 2002, 45, 5786-5796.

54 A. Jinasan, Th. Poonsawat, L. Chaicharoenwimolkul, S. Pornsuwan and E. Somsook, RSC Adv., 2015, 5, 3132431328.

55 A. Singh, D. R. Chowdhury and A. Paul, Analyst, 2014, 139, 5747-5754.

56 R. Fenger, E. Fertitta, H. Kirmse, A. F. Thünemann and K. Rademann, Phys. Chem. Chem. Phys., 2012, 14, 9343-9349.

57 Q. Geng and J. Du, RSC Adv., 2014, 4, 16425-16428.

58 C. Kästner and A. F. Thünemann, Langmuir, 2016, 32, 73837391. 